\section{Revalidating a Merry Christmas}

\author{
S. Hancocks OBE
}

Send your comments to the

Editor-in-Chief,

British Dental Journal

64 Wimpole Street,

London

W1G 8YS

Emailbdj@bda.org
It would be ideal to be able to take this last Editorial page of the year to regale you with a tremendous story about Christmases Past, tales of mulled wine, chestnuts crackling in the heat of a $\log$ fire and the excited voices of children unwrapping treats from under the decoration festooned tree. Ideal, but in all conscience I don't really think it would be a great service. Why? Well, because it would be to pretend in a world that is, I suspect, about to spring some rather unpalatable changes on us all in the not too distant as well as the middle distance future.

In the immediate months to come I think, although I hope I am wrong, that the infamous credit crunch (a suitably orally orientated simile if ever we sought one) will start to bite the hand that treats it. In the same way that the words have become common currency so too is the expression gaining ground that dentistry is not recession-proof but it is potentially recession-resistant. People, patients, are still going to require and need dental treatment but the regularity with which they seek it might dwindle and the extent to which they will be prepared to pay for the more expensive options may take a downward path.

This neatly brings me to the middle distance changes to which I alluded. The GDC currently has a document entitled Developing revalidation. Your chance to get involved which is out for 'comment'. ${ }^{1}$ The Council's intention is to develop the proposals "with our stakeholders before formally consulting on them at the end of 2009'. I would urge you to do as the GDC requests. Carefully reading these early proposals does, I believe, give us a very good idea of the shape into which those regulating us (without our input any longer by electing them remember) intend the profession and professionals to compliantly be moulded. It also enlightens us on the framework in which the Council sees itself championing its now, more than ever, espoused role of protecting the public.

\section{SIGNIFICANT EVENT ANALYSIS}

Based on four categories: professionalism, clinical, communication, and management and leadership, the process envisages a three stage ladder of appraisal beginning with sifting of all dental professionals, continuing to assessment of selected dental professionals and escalating if deemed necessary to in-depth assessment. The document is primarily directed at general dental practitioners and lists a 'menu of sources of evidence' to demonstrate compliance with standards which includes clinical audit/peer review, multi-source feedback, patient satisfaction surveys, CPD compliance and significant event analysis. In many ways it is already a complex scheme of things, anticipating potential appeals and speculating on how different practitioners such as teachers, specialists and those in hospital roles might be affected and might seek to provide the requisite proofs of competency.

My concern is that this complexity, while necessary to establish fairness and equity in the proposed process, veils, like a delicate dusting of Victorian Yuletide snow, a simplicity of message that is all but obscured beneath the layers of detail. In the future, beyond the immediacy of the recession, slightly beyond the ecstasy of the 2012 Olympics but not as far as away as 2020 vision, the shape of dentistry will be far, far more controlled, documented and regulated then ever before. But such degrees of scrutiny involve not only an increasing reliance on judgment, which is expensive, but also a raft of other resources, all of which involve time and all of which cost resources and ultimately money. The document makes no mention at all of financial impact, has no vision of how the time involved is to be conjured and no hint of how individuals might attend to all of this, laudable as it doubtless is in assuring public safety and raising standards, while still actually finding time to treat patients and charge them for the time it takes to build such security. We might have to find a more pragmatic balance between trust, protection and what society at large is prepared to pay than these proposals have yet considered.

I mention all this not to dwell on or spoil a perfectly good and well deserved holiday period but to mull on, as with the spiced infusion I mentioned above. So, may I dispel any gloom and take the opportunity to wish all readers, real and virtual, paper and electronic the very best of the season? I thank you for your continuing valuable contributions, varied and oftentimes surprising comments and wonderfully committed investments in the $B D J$ and look forward to many more in 2009.

1. General Dental Council. Developing revalidation. Your chance to get involved. London: GDC, 2008. Available at www.gdc-uk.org

DOI: 10.1038/sj.bdj.2008.1119 